\title{
Timing of intraventricular haemorrhage
}

\author{
P. EMERSON, M. FUJIMURA, P. HOWAT, D. HOWES, J. KEELING, R. O. ROBINSON, \\ D. SALISBURY, AND J. P. M. TIZARD
}

From the Department of Paediatrics, University of Oxford, and Department of Haematology, Radcliffe Infirmary, Oxford

SUMMARY The detection of the onset of intraventricular haemorrhage (IVH) during life is a necessary preliminary to understanding the cause of this condition. In 10 infants of very low birthweight treated with serial transfusions of adult blood the proportions of transfused cells circulating after each transfusion were compared with the proportion of transfused cells found in the intraventricular clot at necropsy. This allowed the timing of IVH to be restricted retrospectively to the period between consecutive blood transfusions. In addition, the proportional changes of transfused cells produced by infusion of a known red cell mass allow changes in the babies' original red cell mass to be followed during life. A fall in this value occurred in 8 infants dying with IVH and was taken to indicate haemorrhage. Comparison of the two methods in 9 infants suggested that, while in some cases intraventricular bleeding occurs rapidly, in others it takes place over a period of time. The interval between birth and the onset of haemorrhage was directly proportional to the gestational age of the infant.

While there has been a reduction in mortality from hyaline membrane disease in recent years, intraventricular haemorrhage(IVH) remains a major cause of death in low birthweight preterm infants (Fedrick and Butler, 1970; Harcke et al., 1972; Roberton and Howat, 1975). Although the cause of IVH has been a subject of much study and conjecture. it has not yet been explained. To achieve a better understanding of the factors contributing to IVH, events preceding IVH need to be separated clearly from events occurring at the time of IVH and subsequently. Kleihauer (1973) used a technique of differentiating erythrocytes containing haemoglobin $F(\mathrm{HbF})$ from those containing only haemoglobin $\mathrm{A}(\mathrm{HbA})$ for this purpose. Since all the erythrocytes of low birthweight babies contain $\mathrm{HbF}$, the babies' own cells could be distinguished from transfused adult cells. Thus by determining if intraventricular clots contained $\mathrm{HbA}$ cells, Kleihauer was able to decide if intraventricular haemorrhage had taken place before or after blood transfusion. It is evident that most of Kleihauer's 16 low birthweight babies received only one blood transfusion. It has been our practice for several years to give frequent small blood transfusions to ill preterm infants with the object of maintaining peripheral perfusion and oxygenation and thus reducing metabolic acidosis. The $\mathrm{HbA}$ content of the circulating blood rises in steps with

Received 15 May 1976 each transfusion. By comparing the HbA content of the clot, obtained at necropsy, with the changes occurring during life it seemed that it might be possible in fatal cases to determine retrospectively the onset of IVH within narrower time limits than was possible in Kleihauer's cases.

Furthermore, the red cell mass of the infant may be calculated by noting the change in the proportion of transfused cells circulating produced by infusion of a known red cell mass. Since the proportion of the red cell mass which is made up by the baby's own cells (HbF) is known, the changes in the baby's red cell mass from the time of the first transfusion can be followed during life. A fall in this value will indicate haemorrhage. We present details of these methods together with the results of their application to infants dying with IVH.

Chaplin et al. (1976) have used Kleihauer's method to distinguish between red cells in a newborn's cerebrospinal fluid caused by traumatic lumbar puncture and those due to subarachnoid haemorrhage that has occurred before blood transfusion.

\section{Patients and methods}

Observations were made on 16 infants whose birthweights ranged between $650 \mathrm{~g}$ and $1315 \mathrm{~g}$ and gestational ages between 26 and 32 weeks. Blood trans- 
fusions were given when clinically indicated on the basis of falling haematocrit, arterial hypotension, an increase in metabolic acidosis, or to replace diagnostic blood loss; the mean time of the first transfusion was $6 \cdot 5$ hours (range $0 \cdot 5-30$ hours). The donor was checked for congenital persistence of $\mathrm{HbF}$. In a few babies who had already received adult blood for the usual clinical indications, but in whom these indications no longer applied, small $(5-10 \mathrm{ml})$ exchange transfusions were carried out at approximately 6-hour intervals to create regular increments in the percentage of cells containing $\mathrm{HbA}$. We felt this to be justifiable clinically on the basis of increasing oxygen availability to tissues. Thin films were made from umbilical artery blood before and not less than 5 minutes after each transfusion, thus allowing adequate time for mixing of the transfused blood within the infant's circulation.

At necropsy, clot was obtained by aspirating the contents of the lateral ventricles using a widebore needle and a dry syringe. In some cases the fresh brain was cut in order that the whole clot could be examined. Clotted blood was placed in plain tubes and blood films prepared within 6 hours. Thin blood films were prepared from intraventricular clot as follows: an equal volume of isotonic saline was added to the clot and after gently rocking on a rotational mixer for 10 minutes films were then prepared of the red cells suspended in the saline. The films were stained by the technique originally described by Kleihauer et al. (1957) as modified by Shepard et al. (1962).

The percentage of transfused cells was calculated from a sample of 1000 cells counted by two of us (P.E. and D.H.) who had no knowledge of the timing of the transfusion. The coefficient of variability of the estimation was $\pm 4.5 \%$ on seven counts of one sample.

Retrospective timing of IVH by clot analysis depended upon two assumptions. First, the uptake of cells into the intraventricular clot should be representative of peripheral blood. The percentage of transfused cells in peripheral blood was compared directly after sampling with the percentage of transfused cells in the same sample after it had been allowed to clot (Fig. 1). It can be seen that there is close agreement between pairs of results. Second, there should be little variability in the proportion of transfused cells between transfusions. It was found that the variability of $\mathbf{4 8}$ samples taken during 17 periods between transfusions was always within the variability of the method.

The method of calculating the red cell mass of the baby will be described in detail elsewhere but briefly is as follows. The extent by which the proportion of transfused cells in the circula-

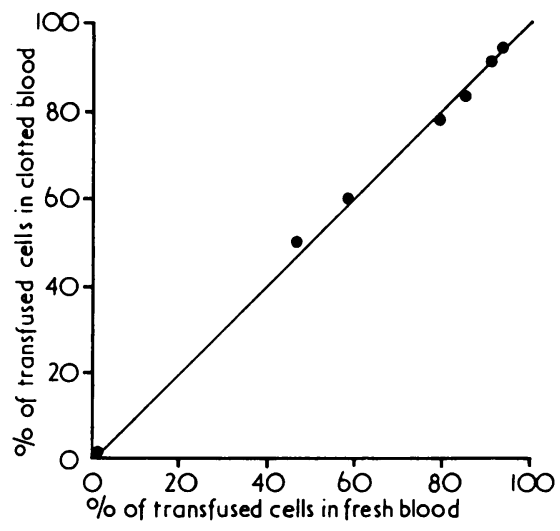

Fig. 1 Relationship between the proportion of cells containing haemoglobin $A$ in fresh and clotted samples from the same blood specimen.

tion rises with a transfusion depends on the red cell mass transfused (which can be measured) and the red cell mass circulating before transfusion (which can therefore be calculated). This method allows an independent calculation of the baby's red cell mass to be made at the time of each transfusion. The baby's red cell mass (V) is given by the expression

$$
\mathrm{V}=\frac{1-\mathrm{a}_{2}}{\mathrm{a}_{2}-\mathrm{a}_{1}} \cdot \frac{\mathrm{v}_{\mathrm{f}}-\left(\mathrm{v}_{\mathrm{f}}-\mathrm{v}_{\mathrm{a}}\right) \mathrm{a}_{1}}{\mathrm{v}_{\mathrm{a}}} \mathrm{T}
$$

where $a_{1}$ and $a_{2}$ are the proportions of transfused cells in the circulation before and after transfusion respectively; $v_{f}$ and $v_{a}$ are the mean red cell volumes of fetal and adult red cells respectively, and $T$ the red cell mass transfused. We have taken figures of $86 \mathrm{sl}\left(\mu^{3}\right)$ (Wintrobe, 1967) and $118 \mathrm{sl}\left(\mu^{3}\right)$ (Klaus and Fanaroff, 1973) for $v_{a}$ and $v_{f}$ respectively.

\section{Results}

The haematologists (P.E. and D.H.) correctly deduced the timing of each of the 40 transfusions by examination of serial slides of peripheral blood.

Clot analysis was successful in 10 of the 16 infants dying with IVH. It was not technically possible to estimate the proportion of transfused cells in the intraventricular clot at necropsy in 6 cases, either because the haemorrhage had occurred a sufficiently long time before death for haemolysis to have taken place, or because there was considerable admixture of brain fragments with clots. In none of the infants had IVH occurred before the first transfusion. Analysis of the clot suggested that the earliest time IVH could have occurred was between 3 and 6 hours 
and the latest was between 72 and 96 hours postnatally. There was a positive correlation between the earliest time IVH could have occurred as judged by clot analysis and the gestational age of the infant (Fig. 2).

Two intraventricular clots have been sampled from multiple areas within the clot $(n=8)$. The variability of the samples from each clot was within the variability of the method. However, in 2 infants evidence was obtained of more than one episode of bleeding. In one, the clot in the left lateral ventricle contained $53 \%$ transfused cells, whereas that in the right lateral ventricle contained $40 \%$ transfused

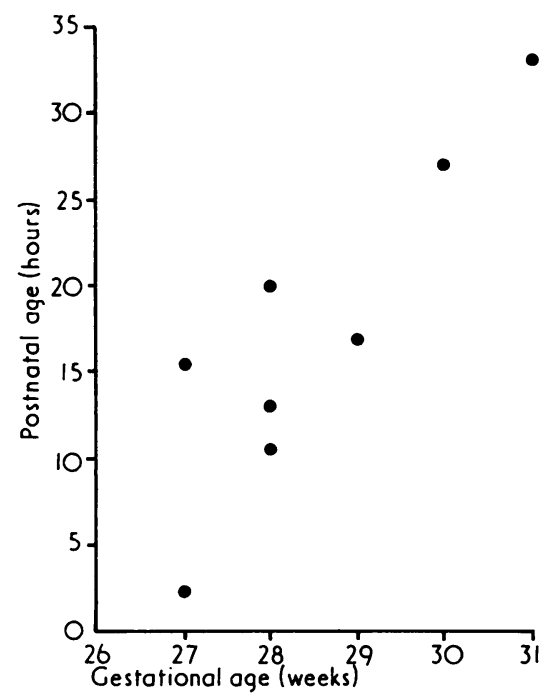

Fig. 2 Relationship between gestational age and onset of IVH.

cells. In the other infant, blood in lumbar CSF obtained by lumbar puncture during life showed $40 \%$ transfused cells, contrasting with the intraventricular clot which contained $83 \%$ transfused cells. Since in both these infants these proportions of transfused cells corresponded to the proportions of transfused cells in peripheral blood in consecutive intertransfusion periods, it is not possible to state the interval between haemorrhages.

The changes in the babies' fetal red cell mass is shown in Fig. 3. A significant fall was judged to have occurred when two values were separated by more than the sum of their standard deviations. In 2 babies the first significant fall agreed with the timing suggested by clot analysis. In one there was no significant fall in fetal red cell mass and haemorrhage as indicated by the composition of the clot had occurred after the last transfusion was given. In 6

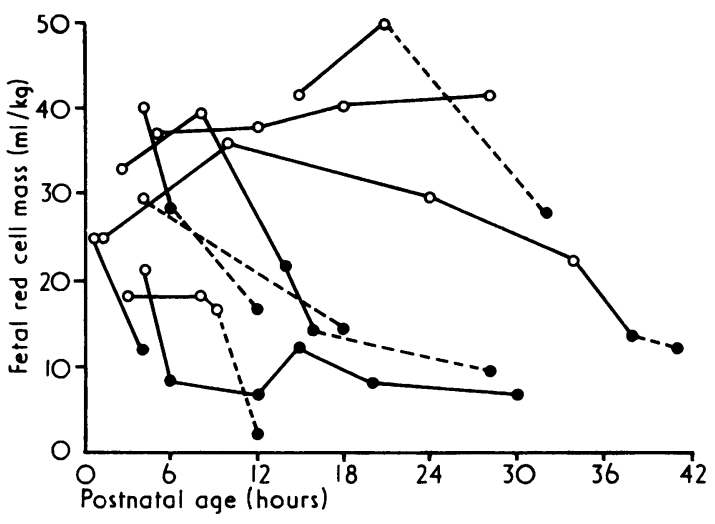

Fig. 3 Changes in fetal red cell mass after birth in babies dying with IVH. $\mathrm{O}=$ Initial values and values not significantly lower than initial values; $0=$ values significantly lower than initial values; - - = period during which IVH occurred as indicated by clot analysis

babies the fall in fetal red cell mass occurred a maximum of $2,2,3,3,6$, and 12 hours before the times suggested by clot analysis. One baby in whom there was an apparent rise in fetal red cell mass from $29 \mathrm{ml} / \mathrm{kg}$ to $113 \mathrm{ml} / \mathrm{kg}$ has been excluded from this figure. The correlation between the earliest time IVH could have occurred as judged by the fall in fetal red cell mass and the gestational age of the infant is upheld.

\section{Discussion}

Comparison of the percentage of cells containing HbA in blood freshly smeared with that in blood allowed to clot showed close correlation. This observation suggests that the intraventricular haemorrhages contained blood which is representative of circulating blood at the time of the haemorrhage. Dyer et al. (1973) showed that clots from unlabelled blood introduced into the lateral ventricles of rabbits did not acquire radioactivity when chromium ${ }^{51}$ tagged red cells were subsequently injected into the peripheral circulation.

The small variation between samples drawn during each period between transfusions suggests that the fate of injected cells was not detectably different from that of the infant cells during the period between the transfusions. It also suggests that augmentation of the circulating volume does not recruit sequestered red cells into the circulation. Dyer et al. (1973) and Tsiantos et al. (1974) have used a technique based on similar principles. They used chromium ${ }^{50}$, a nonradioactive isotope, tagged to red blood cells as a marker for the initial transfusion. The intraventricu- 
lar clot and the samples of peripheral blood were subjected to neutron activation thus converting the chromium ${ }^{50}$ to chromium ${ }^{51}$ and the iron in haem to $\mathrm{Fe}^{59}$. A chromium ${ }^{51}$ : iron ${ }^{59}$ index was derived for each sample. Comparison of the chromium: iron index of the clot with that of the peripheral samples identified the period of the IVH. HbA appears to provide a suitable and less expensive marker provided that haemolysis of the clot has not occurred, and clot substantially free of brain tissue can be obtained.

The changes effected by transfusion afford a means of following changes in red cell mass and, by correction with haematocrit, blood volume. This may be a useful addition to clinical information in conditions where the circulating blood volume is judged to be inappropriately low. We have also followed changes in red cell mass in 9 babies who have survived and in whom we had no reason to suspect occult haemorrhage. In none of these babies did a significant and sustained fall in the baby's fetal red cell mass occur, which suggests that this method also allows the diagnosis of occult haemorrhage to be made during life.

In 9 babies comparison of clot analysis with changes in babies' fetal red cell mass could be made. In 3 there was agreement, but in 6 a fall in fetal red cell mass preceded the time suggested by composition of the clot. It appears, therefore, that in some babies bleeding takes place over a period of time. In some cases by aspirating clot from the ventricles in order to preserve histology or by washing cells from the surface of the clot we may have sampled only the latest of repeated or continuous haemorrhages. This would explain why in all but two of Kleihauer's cases a fall in haematocrit preceded the appearance of transfused cells in the intraventricular clot.

There are at least two possible explanations for the effect of gestational age on the timing of IVH. Either the period between precipitating events and the onset of IVH is determined by the changing structural characteristics of the germinal layer, or the timing - and possibly the nature-of precipitating events varies according to the length of gestation.

Other examples of methods of timing include serial measurements of anterior fontanelle tension using an aplanation transducer and of occipitofrontal circumference; analysis of EEG wave formsthough it must be pointed out that the EEG of sick, very low birthweight infants is already of low voltage; and the use of computerized axial tomography. Simultaneous recording of rectal and peripheral skin temperature and examination of the central/ peripheral temperature difference, while successfully detecting hypovolaemia in older infants
(Aynsley-Green and Pickering, 1974), has not in our hands indicated the timing of IVH in very low birthweight infants. It is clear that the validity of any of these methods will hinge on their relation to the fall in fetal red cell mass.

The object of timing is to evaluate the significance of possible precipitating factors by examining events occurring before the earliest possible time that IVH could have occurred and comparing these events with similar observations in babies dying without IVH or surviving. Injection of hypertonic solutions for example has been suggested as a possible cause of IVH (Simmons et al., 1974; Wigglesworth et al., 1976). Clearly this possibility may be excluded if it is found that administration of alkali occurs predominantly after IVH in an attempt to reverse the resulting acidosis (Roberton and Howat, 1975; Anderson et al., 1976). The relevance of other possible precipitating factors such as arterial and central venous pressures will be the subject of a further communication.

P. H. is in receipt of a grant (G.974/18S/C) from the Medical Research Council, D. M. S. from the Sir William Coxen Trust Fund; and M. F. is a British Council Scholar. The babies were under the care of Drs J. D. Baum, B. D. Bower, H. L. Ellis, D. Pickering, and J. P. M. T. We are indebted to Miss $P$. Townshend and her nursing colleagues for the care of the babies and to Mr Ian Ware for technical assistance.

\section{References}

Anderson, J. M., Bain, A. D., Brown, J. K., Cockburn, F., Forfar, J. O., Machin, G. A., and Turner, T. L. (1976). Hyaline membrane disease, alkaline treatment and cerebral intraventricular haemorrhage. Lancet, 1, 117-118.

Aynsley-Green, A., and Pickering, D. (1974). Use of central and peripheral temperature measurements in care of the critically ill child. Archives of Disease in Childhood, 49, 477-481.

Chaplin, E. R., Schlueter, M. A., Phibbs, R. M., Kitterman, J. A., and Tooley, W. H. (1976). Fetal hemoglobin and the diagnosis of neonatal subarachnoid hemorrhage. Pediatrics, 58, 751-754.

Dyer, N. C., Brill, A. B., Tsiantos, A. K., Sell, E., Victorin, L. H., and Stahlman, M. T. (1973). Timing of intracranial bleeding in newborn infants. Journal of Nuclear Medicine, 14, 807-811.

Fedrick, J., and Butler, N. R. (1970). Certain causes of neonatal death. II. Intra-ventricular haemorrhage. Biology of the Neonate, 15, 257-290.

Harcke, H. T., Naeye, R. L., Storch, A., and Blanc, W. A. (1972). Perinatal cerebral intra-ventricular hemorrhage. Journal of Pediatrics, 80, 37-42.

Klaus, M. H., and Fanaroff, A. A. (1973). Care of the High Risk Neonate, p. 332. Saunders, Philadelphia.

Kleihauer, E. (1973). Feststellung des Zeitpunktes von Intra-kraniellen Blutungen bei Neugeborenen. 5 Deutscher Kongress fur Perinatale Medizin. Perinatale Medizin, 4, 429-435. 
Kleihauer, E., Braun, H., and Betke, K. (1957). Demonstration von fetalen Hämoglobin in den Erythrocyten eines Blutausstrichs. Klinische Wochenschrift, 35, 637-638.

Roberton, N. R. C., and Howat, R. (1975). Hypernatraemia as a cause of intra-cranial haemorrhage. Archives of Disease in Childhood, 50, 938-942.

Shepard, M. K., Weatherall, D. J., and Conley, C. L. (1962). Semi-quantitative estimation of the distribution of fetal hemoglobin in red cell populations. Bulletin of the Johns Hopkins Hospital, 110, 293-310.

Simmons, M. A., Adcock, E. W., III, Bard, H., and Battaglia, F. C. (1974). Hypernatraemia and intra-cranial hemorrhage in neonates. New England Journal of Medicine, 291, 6-10.
Tsiantos, A., Victorin, L., Relier, J. P., Dyer, N. Sundell, H., Brill, A. B., and Stahlman, M. (1974). Intra-cranial hemorrhage in the prematurely born infant. Journal of Pediatrics, 85, 854-859.

Wintrobe, M. M. (1967). Clinical Hematology, 6th ed. Lea and Febiger, Philadelphia.

Wigglesworth, J. S., Keith, I. H., Girling, D. J., and Slade, S. A. (1976). Hyaline membrane disease, alkali, and intraventricular haemorrhage. Archives of Disease in Childhood, 51, 755-762.

Correspondence to Professor J. P. M. Tizard, Department of Paediatrics, John Radcliffe Hospital, Headington, Oxford OX3 9DU. 